\title{
Determinants of hospital efficiency: A literature review
}

\author{
Eyob Z. Asbu, Maysoun D. Masri, Marwan Al Naboulsi \\ Department of Health, Health System Financing Division, Abu Dhabi, United Arab Emirates
}

Received: March 13, 2020

Accepted: May 7, 2020

Online Published: May 15, 2020

DOI: $10.5430 /$ ijh.v6n2p44

URL: https://doi.org/10.5430/ijh.v6n2p44

\begin{abstract}
Background: Inefficiency is a pervasive problem in health systems. The World Health Organization estimates that on average, $20 \%-40 \%$ of the global total health expenditure is wasted. The proportion of total health expenditure attributed to hospitals is high, which implies that improving the efficiency of hospitals will lead to more efficient health systems. This study aims to synthetize the major determinants of hospital inefficiency and to develop a framework to identify causes of inefficiency and develop multi-factor interventions to address inefficiencies.

Methods: The study is based on survey of the literature on the determinants of hospital efficiency. The studies include those that employ ratio methods of efficiency analysis, data envelopment analysis and stochastic frontier models and econometric models such as the Tobit regression to assess determinants of technical efficiency. Data was extracted in a table format categorized as those that are within the hospital, outside the hospital but within the health system and those that are outside the hospital and health system in the broader macroeconomic system and analyzed.

Results: Hospital efficiency is influenced by factors that may be internal to the hospital or external and thus could be wholly or partially out of the control of the hospital. Hospital-level characteristics that influence efficiency include ownership, size, specialization/scope economies, teaching status, membership of multihospital system and other factors such as case-mix and ratio of outpatients to inpatients. However, the effects of these variables are not definitive and consistent; all depends on the context. Factors out of the direct control of the hospital include geographic location, competition and reimbursement systems. The findings further elucidate that no single factor is effective in addressing hospital inefficiencies in isolation from others.

Conclusion: There is no one single magic formula or intervention that can be adopted by different hospitals to improve hospital efficiencies. Multiple factors influence the efficiency of hospitals. To address hospital inefficiency multi-intervention packages focusing on the hospital and its environment should be developed.
\end{abstract}

Key Words: Hospital, Efficiency, Inefficiency, Waste, Determinants

\section{BACKGROUND}

Inefficiency is a pervasive problem in health systems. The World Health Organization (WHO) estimates that on average, $20 \%-40 \%$ of global total health spending is wasted. ${ }^{[1]}$ In 2011, the annual cost of waste to the US health care system was estimated between a low of $21 \%$ and a high of $47 \%$ of the total health expenditure. ${ }^{[2]}$
Improving efficiency of health systems has gained increased attention due to rapid growth in health expenditure driven by factors that include demographic and epidemiological changes, growth in health technology and rising expectations of the population. ${ }^{[3]}$ The 2018 Declaration of Astana on Primary Health Care aptly states that the global community cannot afford waste in health care spending due to inefficiency if universal health coverage and other health and

*Correspondence: Eyob Z. Asbu; Email: zeyob@yahoo.com; Address: Department of Health, Health System Financing Division, P.O. Box 5674, Abu Dhabi, United Arab Emirates. 
health-related targets of the Sustainable Development Goals are to be achieved. ${ }^{[4]}$

Hospitals consume a large proportion of the total health expenditure. In the Organization for Economic Cooperation and Development (OECD) member states, hospitals, on average absorbed about $38 \%$ of the total health expenditure in 2016. Figures for some of the high-income OECD countries during the same period include, Germany (29.1\%), USA (34\%), Canada (29.3\%), the UK (41.7\%), Italy (45.5\%), France $(38.4 \%)$ and Denmark (44.3\%). ${ }^{[5]}$ In low and middleincome countries, the proportion of total health expenditure attributed to hospitals is even higher $-51 \%$ in South Africa in 2013/2014 $4^{[6]}$ and 53\% in Malaysia in 2015. ${ }^{[7]}$ For this reason, assessment of hospitals efficiency has gained the utmost attention of policy makers and managers, as efficient hospitals imply better health systems. ${ }^{[8,9]}$

Many studies have indicated that technical inefficiency in hospitals is widespread in countries at all stages of economic development. Globally about US\$ 300 billion is lost annually to hospital-related inefficiency. ${ }^{[10]}$ It is therefore imperative to look for the factors influencing hospital efficiency and propose interventions to improve hospital efficiency and performance of the entire health system. This paper has dual objectives. First, information on major determinants of hospital efficiency will be synthesized using a literature search. Second, a framework for addressing hospital inefficiency will be proposed based on the synthesis of the problems.

Hospital inefficiencies exist in different forms including technical, allocative, scale, scope and cost inefficiency. ${ }^{[11]}$ A hospital is technically efficient when it maximizes outputs for a given level of inputs or resources, or conversely, when it minimize inputs for a given level and choice of outputs. Allocative efficiency is when a hospital allocates and uses the least costly combination of inputs in producing its outputs or when hospital resources are committed to produce outputs that are priorities for society. Scale efficiency exists when the size of hospital operations is optimal so that any modifications of its size will render the hospital less efficient. Scope efficiency occurs when a hospital reduces its average cost through the benefit of producing several outputs. Cost efficiencies measure the average cost used in producing outputs compared to a standard or the cost used by other providers.

A hospital is an institution that provides beds, meals, and constant nursing care for its patients while they undergo medical therapy at the hands of a physician with the objective of restoring the patient to health. ${ }^{[12]}$ This definition covers the main attributes of a hospital. However, hospitals are diverse entities in terms of their structure and organization. They range from a small rural hospital in a low-income country, which provides basic services to a large specialized urban hospital in a high-income country endowed with the latest technology and highly skilled workforce.

The core functions of hospitals include patient care, teaching, research and health system support. ${ }^{[13]}$ However, the extent to which hospitals execute some of these functions depends on how they are organized and classified. These will expectedly have an effect on the efficiency of hospitals and the factors that influence efficiency. Hospitals can be divided into different categories based on various criteria ${ }^{[14]}$ including:

(1) Ownership - public and private hospitals;

(2) Financial objective - for profit (FP) and not for profit (NFP) hospitals;

(3) Educational responsibilities - teaching hospital (TH) and non-teaching hospital (NTH);

(4) Hierarchical classification - primary, secondary and tertiary hospitals;

(5) Degree of service specification: general and specialized hospitals; and

(6) Employee status of their doctors: staff model and nonstaff model hospitals.

A combination of the above criteria may be used in classifying hospitals. For example, private hospitals may be classified as private for profit (PFP) or private not for profit (PNFP).

\section{Measurement of hospital efficiency}

A hospital consumes various inputs (human resources, pharmaceuticals, equipment, etc.) to produce valued outputs (outpatient visits, surgical operations, etc.). The analysis of hospital efficiency is concerned with measuring the competence with which inputs are converted to valued outputs. ${ }^{[15]}$ The efficiency of hospitals has two variants, technical (production) efficiency and allocative efficiency. ${ }^{[16]}$ Technical efficiency has input and output orientations. Using input-oriented definition, a hospital is considered technically efficient when it minimizes the use of inputs in producing its chosen outputs. In an alternative, but equivalent output-oriented definition, a hospital is technically efficient when it maximizes its outputs given its chosen level of inputs. Technical efficiency is decomposed into pure technical (operational) efficiency and scale efficiency. When a hospital does not operate at constant returns to scale, it suffers from inefficiencies due to economies and diseconomies of scale.

The second variant of hospital efficiency, allocative efficiency, examines the choice of hospital outputs or inputs. Input-oriented allocative efficiency examines whether a hospital employs the optimal mix of inputs (factors of produc- 
tion) to produce its chosen outputs given prevailing input prices. On the output side, allocative efficiency examines whether a hospital uses scarce resources to produce the correct mix of outputs that maximize societal health gains in aggregate.

Hospital efficiency is measured using various methods including ratios and frontier techniques founded on microeconomic theory of production. Ratios are piecemeal measures of capacity utilization and unit costs and do not take the multiple input, multiple-output nature of hospital production. Frontier techniques rectify this limitation of ratio methods. The two common forms are data envelopment analysis, which is non-parametric, data driven technique that employs mathematical programming; and parametric stochastic frontier techniques that use econometric methods and include production and cost functions. ${ }^{[17]}$ In measuring determinants of efficiency, many studies use a two-stage method. ${ }^{[18]}$ They first compute the efficiency scores and then regress these against hypothesized explanatory variables to assess their effect on (in)efficiency.

\section{Methods}

The study is based on survey of the literature on hospital efficiency and its determinants. The studies include those that employ ratio methods of efficiency analysis, data envelop- ment analysis and stochastic frontier models and econometric models such as the Tobit regression to assess determinants of technical efficiency. Data was extracted in a table format categorized as those that are within the hospital, outside the hospital but within the health system and those that are outside the hospital and health system in the broader macroeconomic system.

\section{Search strategy}

Relevant studies for this review were identified from PubMed, references cited in selected articles and grey literature that includes reports and guidelines from the WHO, OECD and working papers from academic institutions.

The search terms used were "((determinants [Title/Abstract]) AND (hospital [Title/Abstract])) AND (efficiency [Title/Abstract])." There is no limit in the time covered by the literature. The search result yielded 133 articles. The first article in the search result with PMID 28940917, titled "Determinants of transient and persistent hospital efficiency: the case of Italy," was found to be the most relevant. Hence, it was decided to search all articles similar to PMID 28940917. The literature search was conducted in March 2019.

The process followed in identifying appropriate materials for the literature review is depicted in Figure 1.

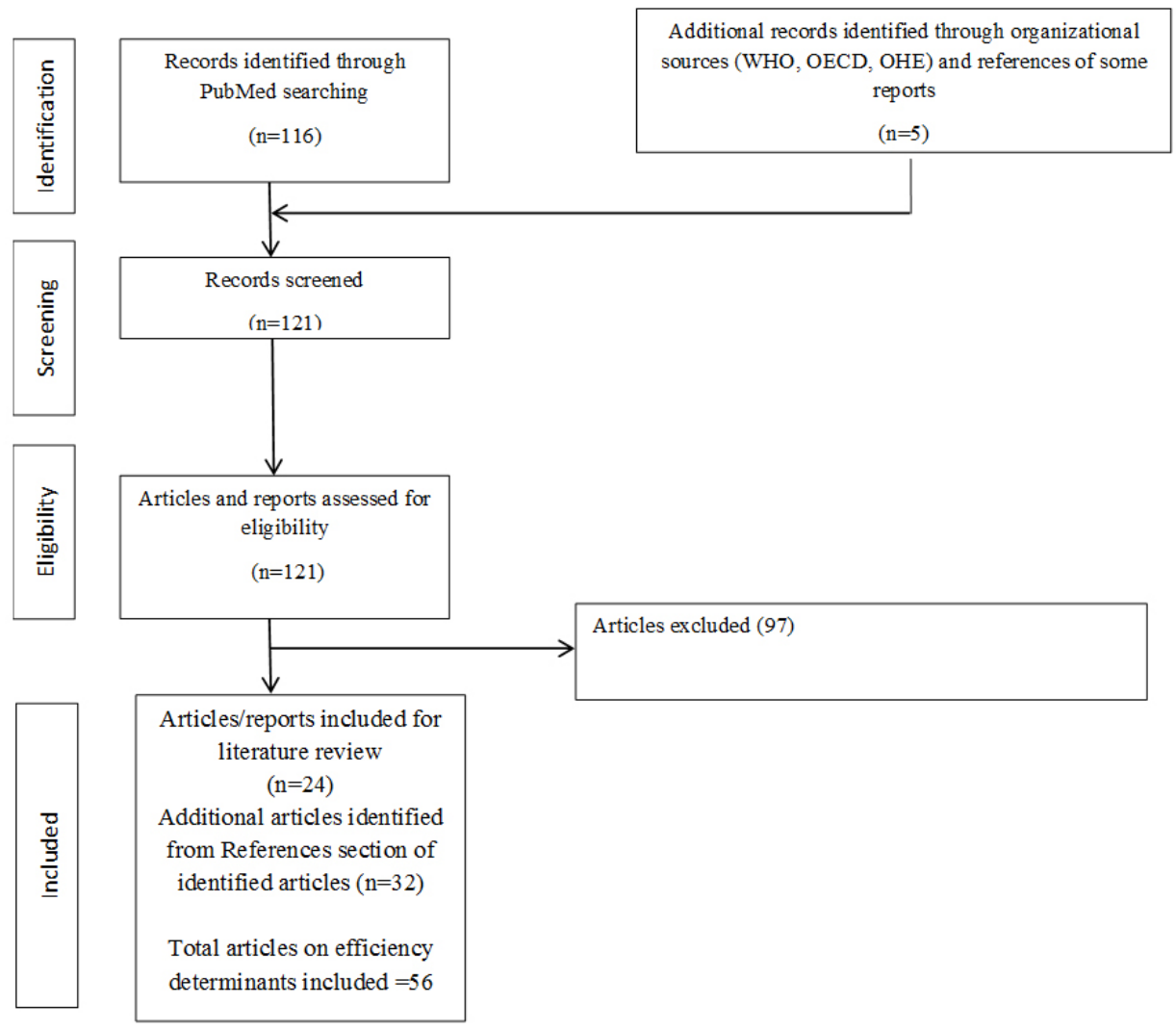

Figure 1. Flow chart of search results of studies from searching and screening 


\section{Results}

\subsection{General}

The majority of the articles (75\%) surveyed pivoted on hospital-level determinants of efficiency including factors such as ownership, size, teaching status and degree of specialization, among others. The extra-hospital determinants focus on provider re-imbursement mechanisms, geographic location and competition (see Table 1).

Table 1. Reviewed articles by area of focus

\begin{tabular}{|c|c|c|}
\hline Level & Factor & No. of articles \\
\hline \multirow{6}{*}{$\begin{array}{l}\text { Hospital- } \\
\text { level } \\
\text { factors }\end{array}$} & Ownership & 15 \\
\hline & Size & 6 \\
\hline & Specialization & 5 \\
\hline & Teaching status & 6 \\
\hline & Membership of multihospital system & 4 \\
\hline & $\begin{array}{l}\text { Other factors (case-mix index, occupancy rate, } \\
\text { outpatient-to-inpatient ratio) }\end{array}$ & 7 \\
\hline \multirow{3}{*}{$\begin{array}{l}\text { Extra- } \\
\text { hospital } \\
\text { factors }\end{array}$} & Geographic location & 3 \\
\hline & Competition & 5 \\
\hline & Reimbursement system and provider incentives & 5 \\
\hline
\end{tabular}

\subsection{Hospital-level factors}

\subsubsection{Ownership}

The evidence regarding the effect of hospital ownership on efficiency is mixed, and depends on a number of factors including the country and geographical location of the hospital under investigation, the hospital structure and its financing schemes, in addition to the methods and the comparative data sets used in measuring efficiency. ${ }^{[19-21]}$ While some studies indicate that private FP hospitals are more efficient than private NFP hospitals, ${ }^{[22-24]}$ others, to the contrary, show that private NFP hospitals are more efficient than private FP ones. $^{[25-27]}$ As profit making is the key component of the mission of FP hospitals, increased profits could be achieved through increased efficiencies. ${ }^{[28]}$ Other research concluded that government/public hospitals are more technically efficient than private NFP ones and that hospitals in general facing greater financial pressure tend to improve their efficiency. ${ }^{[29]}$ To the contrary, a study in Germany examining changes in efficiency after privatization demonstrated that conversion from public to private for-profit status resulted in an increase in efficiency between $2.9 \%$ and $4.9 \%$, which also appeared to be permanent rather than a transient change. ${ }^{[9]}$ Still others have concluded that there is no clear evidence that private hospital ownership - non-profit and for profits - is associated with higher efficiency compared to public hospital ownership. ${ }^{[30,31]}$

\subsubsection{Size}

Optimum hospital operational scale is a function of patient access, economies of scale and volume as a determinant of patient outcome. ${ }^{[32]}$ Economies of scale characterize a situation in which fixed costs of production are higher relative to variable costs. ${ }^{[32,33]}$ Economies of scale exist when long-run average costs decrease as the scale or volume of production increases. The existence of economies of scale implies that efficiency gains could be reaped by expanding hospital size. Optimum hospital size is seen when all economies of scale have already been exploited but have not yet reached a point of diseconomies of scale, where long-run average costs start to increase as the hospital size (scale of production) increases. Smaller hospitals might be inefficient because of their inability to spread fixed (overhead) and administrative costs across a greater number of cases/patients.

In a study assessing the technical and allocative efficiency of Greek public hospitals, it was found that small hospitals were the least efficient (technical efficiency score $=0.80$ ) in comparison with medium-sized (0.86) and large (0.90) hospitals. ${ }^{[34]}$ On the other hand, in a study of Turkish hospitals, small hospitals were found to be relatively more efficient compared to medium and large hospitals and had better patient satisfaction. ${ }^{[35]}$ Research suggests that a hospital can take full advantage of economies of scale when its size ranges between 200-300 beds, while diseconomies of scale occur when a hospital size is below 200 and above 600 beds. ${ }^{[36]}$ A systematic review on the scale efficiency of hospitals has reported that there is scale inefficiency when the hospital size is below 200 beds and over 600 beds. ${ }^{[37]}$ This implies that from the efficiency perspective, the optimal hospital bed capacity lies between 200 and 600 beds.

\subsubsection{Specialization vs. economies of scope}

The range of products offered by a hospital affects efficiency. However, the direction of influence is unpredictable. Multi-output production sometimes enables achievement of economies of scope and at other times results in diseconomies of scope. Scope economies occur when the joint production of two or more products (e.g., inpatient and outpatient services) can be achieved at lower costs than the combined cost of producing each output individually. In other words, a general hospital is more efficient than a specialized hospital. The opposite effect is seen when there are diseconomies of scope.

In their study of 133 Italian hospitals, Colombi et al. found that hospitals specialized in single treatments have higher transient inefficiency than general hospitals, indicating economies of scope. ${ }^{[19]}$ In the same vein, a study in three States of the USA using stochastic frontier cost function presented some evidence that general hospitals are more efficient than specialized ones. ${ }^{[38]}$ A study using an extensive panel dataset in England classified sources of heterogeneity 
in hospital services into two: ${ }^{[39]}$

(1) Admission-type heterogeneity, which results from collocating the treatment of elective and emergency patients within the same hospital; and

(2) Service-line heterogeneity, which is the result of collocating a number of clinical specializations within the same hospital.

The findings indicate the presence of negative economies of scope across the two types of admission - increased volume of elective admission to a hospital was associated with an increase in the cost of emergency care. Moreover, for emergency admissions, there was evidence of economies of scope across service lines, that is, increased emergency activity in one service line is associated with lower cost of emergency care in other service lines. No evidence of economies of scope was found across service lines for elective admissions.

In a developing country setting, a study from Vietnam reported evidence of modest economies of scale, which differed by category of hospital - economies of scope greater in provincial general hospitals than in central general hospitals. The question about economies of scope assessed whether it was less expensive to provide both inpatient and outpatient services at the same hospital than to have a separate facility for outpatient services. ${ }^{[40]}$

\subsubsection{Teaching status}

Some studies indicate that THs were found to be less efficient than NTHs due to a number of factors including the use of medical residents instead of attending (staff) physicians who are more experienced in caring for patients. ${ }^{[41,42]}$ Using DEA and Tobit regression analysis, a study in Greece during the period of financial crisis 2009-2012 demonstrated that university hospitals are less efficient compared with non-teaching hospitals due to multiplicity of functions including teaching and research in addition to patient care. ${ }^{[9]}$ Grosskopf et al. found that inefficiency attributed to congestion or the excess use of residents amounted to $20 \%$ of the total inefficiency score in teaching hospitals. ${ }^{[43]}$ In the presence of congestion inefficiency, the increase of inputs over a given level results in a decrease of outputs. The teaching status of a hospital often requires conducting additional clinical tests and diagnostics for the benefit of the residents implying that teaching hospitals are likely to use higher level of resources than nonteaching hospitals for producing the same level of output. $^{[44]}$ An empirical study of the determinants of hospital efficiency in Italy using four-random-component stochastic frontier model did not find statistically significant effect of teaching hospitals on transient (short-term) and permanent (long-term) inefficiency. ${ }^{[19]}$

\subsubsection{Membership of multihospital system}

Hospitals that do not belong to a multihospital system or are standalone have low efficiency scores. ${ }^{[26]}$ It is argued that, when a hospital is part of a system, greater efficiency is achieved, as the production of multiple products in different hospitals within the system could only be achieved by the employment of highly specialized group of managers and technical experts, and the elimination of duplicative administrative functions. ${ }^{[45]}$ In a recent research, comparing performance, operating characteristics, and market environments of low- and high-efficiency hospitals in 37 states in the USA, high-efficiency hospitals tended to be members of multihospital systems, non-teaching, and investor-owned. ${ }^{[46]}$ The benefits of system membership depends greatly upon the characteristics of the system. Membership in centralized physician/insurance or decentralized systems was associated with improved efficiency compared with those that are members of independent systems. ${ }^{[47]}$

\subsection{Other hospital-level factors}

A number of studies indicate that other internal hospital factors (including the case-mix index, occupancy rate, and outpatient to inpatient ratio), which are related to managerial style and performance may all significantly affect hospital efficiency.

A research of Japanese hospitals investigating the link between managerial performance and hospital efficiency found that setting and monitoring financial parameters linked to managerial performance had a significant positive relationship with hospital efficiency. ${ }^{[48]}$

The case mix index (CMI), which is usually used as a categorization scheme to assess the level of severity/complexity of cases treated by a hospital is one of the main factors accountable for differences in cost per case between hospitals. ${ }^{[32]}$

Hospitals with higher bed occupancy rates may be more efficient. A study of referral hospitals in Uganda indicated that bed occupancy was among the significant factors explaining variations in hospital efficiency. ${ }^{[49]}$ A similar study examining the efficiency of 112 Greek public hospitals, also found a positive relationship between occupancy rate and efficiency. ${ }^{[50]}$

Shifting the delivery of healthcare from a hospital inpatient setting to ambulatory setting, and reduction of the average length of hospital stay are other factors that have been generally adopted by policy makers to promote efficiency and control hospital spending. This trend has led to a decline in the number of hospital beds per capita in most European countries over the past two decades. ${ }^{[51,52]}$ 


\subsection{Extra-hospital factors}

\subsubsection{Geographic location}

According to location theory, an efficient location is presumably one in which some societally predetermined level or volume of service is met at minimum total system costs of operation and travel, or alternatively, one that maximizes the volume of service within a predetermined budget constraint. ${ }^{[53]}$ A number of studies found that hospitals in relatively remote or rural areas were mostly less efficient than hospitals in urban areas. This is not surprising because the primary role of these hospitals is to provide basic healthcare services to the population as the safety-net providers. As such, hospitals in rural and remote areas are not as busy as those in urban areas. This results in the presence of unused capacity including underutilized inputs such as doctors and other healthcare professionals leading to lower efficiency scores. ${ }^{[44]}$ However, hospital efficiency scores may change when hospitals are evaluated against their own peer groups. ${ }^{[54]}$

\subsubsection{Competition}

A number of studies investigated the effect of competition on hospital production and efficiency. ${ }^{[55]}$ Analyzing the relationship between competition and efficiency is a difficult task due to the complexity of health systems and their structures. Furthermore, the potential role for competition in healthcare is often mixed. ${ }^{[56]}$ Competition occurs when producers try to attract customers from their competitors by providing a more appealing combination of price and quality. In conventional markets, this may lead to greater efficiency; however, it is not always the case in the healthcare market. ${ }^{[57]}$ A study in 2001-2004, assessing the effects of competition on efficiency among hospitals in Florida found that hospitals located in a less competitive market had lower technical efficiency scores than those in a more competitive market. ${ }^{[58]}$ In contrast, research in Turkey indicates that hospital efficiency is not significantly affected by the intensity of competition among hospitals. ${ }^{[59]}$

\subsubsection{Reimbursement systems and provider incentives}

The introduction of DRG-based prospective payment system was often found to have negative effects on hospitals' length of stay and positive effects on efficiency. ${ }^{[60]}$ A number of studies conducted in the US and Europe indicate that the introduction of DRGs resulted in a positive shift in efficiency. ${ }^{[61-64]}$

\section{DISCUSSION}

Results of this study highlight that a host of factors influence the efficiency of hospitals. These range from hospital-level characteristics to other health system-level factors and those that are outside the health system in the broader economic formation. The hospital as an open system nested within the health system and other higher-level systems must interact with those systems (its environment) for survival, adaptation and growth. ${ }^{[65]}$ Hence, assessment of the causes of hospital inefficiency must view the hospital in the context of its environment. Furthermore, the study underscores the fact that there is no single cause of hospital inefficiency; it is rather multifactorial. Therefore, solutions aimed at addressing hospital inefficiency should be multi-intervention packages focused on the hospital and its environment.

The surveyed literature has not shown effect of the three types of ownership (public, PFP and PNFP) on hospital efficiency conclusively. Arguments based on theories including property rights theory, agency theory and public choice theory have concluded that private-for-profit hospitals are likely to achieve greater efficiency due to an assumed hospital behavioral objective of profit maximization attributed to the right to appropriate surplus finances, and non-interference by politicians whose objectives may be at odds with profit maximization. ${ }^{[30]}$ In common usage, ownership implies the right to purchase or dispose of any assets of an organization including any financial surplus resulting from the process of production. This notion of ownership does not necessarily indicate the behavioral objective(s) of different forms of hospital ownership. ${ }^{[66]}$ Hence, ascribing the profit maximization motive based on ownership and concluding that PFP hospitals tend to be more efficient compared to the public and PNFPs may not be necessarily true. PFP hospitals may also have other competing objectives such as patient welfare, quest for prestige/reputation, excellence in research and teaching. Moreover, market failures such as barriers to entry and asymmetry of information; the mix of providers and purchasers and how they interact; the prevailing contractual and regulatory arrangements; the incentives in place; and the extent of out-of-pocket payment or third party payment are among the contextual factors that may constrain efficiency related to private for-profit ownership. ${ }^{[66,67]}$ This finding is important for policy makers, as it implies that private provision alone does not enhance efficiency in the hospital system and that a thorough analysis of enabling factors is crucial before a decision to privatize.

Studies have identified that scale economies exist in hospitals with bed-capacity less than 200 and diseconomies in those with bed capacity over 600 , implying optimal capacity between 200 and 600 beds. The optimum size depends on a number of factors including location, population served and health system policies that they wish to implement. Scale inefficiency concerns have driven a number of countries to implement merger of hospitals. Cost savings were realized immediately after hospital merger. ${ }^{[37]}$ The cost savings are attributed to: (i) reduced duplication and lower administra- 
tive costs; (ii) strengthened buying power of the hospital as a purchaser of goods and services; and (iii) spreading of the cost of common resources (e.g., theatres and diagnostic equipment) across a larger volume. ${ }^{[68]}$ It should, however, be noted that in a private health care market, mergers may also be primarily focused on reducing competition and boosting profitability. ${ }^{[32]}$ On the other hand, to improve the efficiency of hospitals that are too big and facing diseconomies of scale, downsizing of hospitals has been implemented. ${ }^{[37]}$

Membership of multihospital system is regarded to operate via individual hospital-level scale and scope economies. This includes improved bulk purchase of inputs such as human resources and reduced interest rate in capital markets, elimination of duplicative administrative functions, economies in marketing a large organization and greater ability to control environmental factors. ${ }^{[47]}$

The range of products offered by a hospital may affect efficiency. However, the direction of influence is unpredictable as can be inferred from the results section. Multi-output production sometimes enables achieving economies of scope and at other times results in diseconomies of scope. Decisions on whether or not to co-locate different functions such as emergency vs. inpatient or outpatient vs inpatient care, and different clinical specialties should be based on a thorough analysis of the contextual factors that are likely to affect scope economies.

Enhancing managerial performance and hospital processes which could be achieved through different initiatives ranging from the use of bonuses as an instrument for regulating work incentives to reduce on labor costs, to merging hospitals or restructuring them into clinics; to replacing total budget accounting and introducing detailed accounting for various expenditures were all found to improve efficiency. Furthermore, the introduction and addition of DRG case mix index in a stochastic frontier efficiency analysis and factors influencing hospital efficiency resulted in a $50 \%$ reduction in inefficiency. ${ }^{\text {[69] }}$

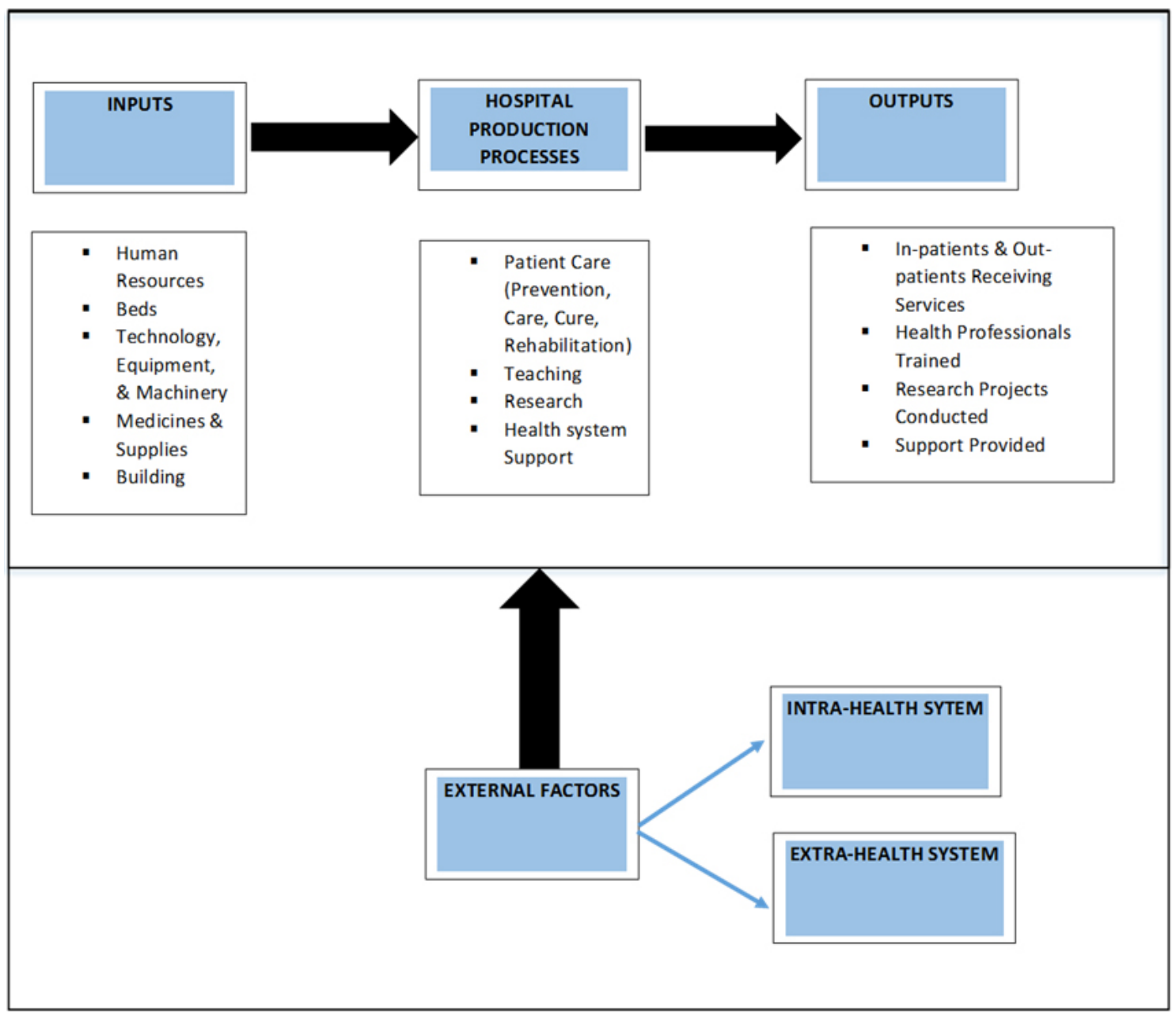

Figure 2. Hospital production function and efficiency framework 


\section{Developing a hospital efficiency framework}

The preceding discussion revealed that various factors determine the level of hospital efficiency including hospital size, patient case-mix, ownership, location, teaching status, reimbursement system used and others. ${ }^{[8,37,67]}$ These factors can be classified broadly as factors that are internal and/or external to the hospital. ${ }^{[19]}$ Furthermore, understanding the determinants of hospital efficiency entails a proper examination of hospital production function, which portrays the relationship between factor inputs (such as human resources, beds, medicines and technologies, etc.) and the outputs of a hospital (such as inpatient and outpatient services, number of health professionals trained etc.). Thus, the efficiency with which a hospital produces its valued outputs is influenced by factors that may be wholly or partially out of the control of the hospital. Figure 2 depicts this framework.

Thus, the technical and allocative efficiency of a hospital may be influenced at the level of the elements of the production function and their linkages (the upper half of the box - see Figure 2) and/or factors that emanate outside the hospital both from within the wider health system and outside the purview of the health system. Accordingly, these factors can be clustered around two broad categories as:

(1) Hospital-level factors, which are within reach and can be addressed by the hospital;

(2) External influencing factors, which are not within easy reach of the hospital and require interventions from higher levels of the wider health system or other relevant sectors outside the health system.

\section{Conclusion}

The study shows that identification of specific determinants of hospital efficiency is a necessary step towards designing interventions to improve potential inefficiencies. There is no single standalone intervention that is effective in improving hospital efficiency; a multi-intervention package tuned to the context is rather required.

An abundance of research have appeared over the years intending to assess hospital inefficiencies, however, few have had any impact on corrective actions taken or new policies adopted by policy makers or hospital management. ${ }^{[70,71]}$ Thus, one main lesson and recommendation that could be drawn from this literature review, is that there is no single magic formula or policy that can be adopted by different hospitals and can be effective in improving hospital performance and efficiencies. It is essential to identify the set of determinants of efficiency for each hospital so that targeted policies could be planned and implemented accordingly. The identification of specific determinants of hospital efficiency and establishing the efficiency performance framework for each hospital is a necessary step toward designing interventions to improve potential inefficiencies.

\section{Limitations of the study}

This study has the following major limitations, which should be taken into account:

(1) The study is not a systematic review nor a metaanalysis. Hence, it is not comprehensive in its coverage of the literature on the determinants of hospital efficiency.

(2) The study's focus is on surveying the literature on the determinants of hospital efficiency. It does not delve deep into types of efficiency and measurement techniques.

\section{CONFLicts OF INTEREST Disclosure}

The authors declare no conflicts of interest.

\section{REFERENCES}

[1] World Health Organization. The world health report: health systems financing: the path to universal coverage. Geneva: World Health Organization; 2010.

[2] Berwick DM, Hackbarth AD. Eliminating waste in US health care. JAMA. 2012; 07(14): 1513-1516. PMid:22419800. https ://doi . org/10.1001/jama.2012.362

[3] OECD. Value for money in health spending. Paris: Organization for Economic Cooperation and Development; 2010.

[4] World Health Organization, United Nations Children's Fund. Global Conference on Primary Health Care: Declaration of Astana. Astana, Kazakhstan; 25-26 October 2018. Available from: https://www. who.int/docs/default-source/primar

Published by Sciedu Press y-health/declaration/gcphc-declaration.pdf (accessed 28 October 2018).

[5] OECD. Health expenditure and financing. Available from: https : //stats.oecd.org/Index.aspx?DataSetCode=SHA (Accessed 25 Sep 2018).

[6] National Department of Health. National health accounts estimates for South Africa 2013/2014 - towards national health insurance and the 2030 National Development Plan. Pretoria, South Africa; 2017.

[7] Ministry of Health Malaysia. Malaysia national health accounts: health expenditure report 1997-2015. Putrajaya, Malaysia; 2017.

[8] Tiemann O, Schreyögg J. Changes in hospital efficiency after privatization. Health Care Manag Sci. 2012; 15: 310-326. PMid:22297925. https://doi.org/10.1007/s10729-012-9193-z 
[9] Xenos P, Yfantopoulos J, Nektarios M, et al. Efficiency and productivity assessment of public hospitals in Greece during the crisis period 2009-2012. Cost Eff Resour Alloc. 2017; 15: 6. PMid:28450811. https://doi.org/10.1186/s12962-017-0068-5

[10] WHO. WHO global health expenditure atlas. Geneva: World Health Organization; 2014.

[11] Rosko MD. Impact of internal and external environmental pressures on hospital inefficiency. Health Care Management Science. 1999; 2(2): 63-74. PMid:10916603. https ://doi .org/10.1023/A : 10 19031610741

[12] Miller TS. The birth of hospitals in the Byzantine Empire. In McKee M, Healey J (Eds.). Hospitals in a changing Europe. World Health Organization: European Observatory of Health Care Systems; 2002.

[13] Healey J, McKee M. The role and function of hospitals. In McKee M, Healey J (Eds.). Hospitals in a changing Europe. World Health Organization: European Observatory of Health Care Systems; 2002.

[14] Liu X, Mills A. In Preker AS, Liu X, Velenyi EV, Baris E (Eds.). Public ends, private means: strategic purchasing of health services. Washington, DC: The World Bank; 2007.

[15] Cylus J, Papanicolas I, Smith PC. How to make sense of health system efficiency comparisons. World Health Organization: European Observatory on Health Systems and Policies, Policy Brief 27; 2017. Available from: http://www.euro.who.int/_data/assets/pd f_file/0005/362912/policy-brief-27-eng.pdf?ua=1

[16] Coelli TJ, Prasada Rao DS, O’Donnell CJ, et al. An Introduction to efficiency and productivity analysis. New York: Springer Science; 2005.

[17] Zere E, Mbeeli T, Shangula K, et al. Technical efficiency of district hospitals: evidence from Namibia using data envelopment analysis. Cost Effectiveness and Resource Allocation. 2006; 4: 5. PMid:16566818. https://doi.org/10.1186/1478-7547-4-5

[18] Zere E. Hospital efficiency in Sub-Saharan Africa: evidence from South Africa. United Nations University: World Institute for Development Economics Research, Working Papers No. 187; 2000. Available from: https://www.wider.unu.edu/sites/default/files/ wp187.pdf

[19] Colombi R, Martini G, Vittadini G. Determinants of transient and persistent hospital efficiency: the case of Italy. Health Economics. 2017; 26: 5-22. PMid:28940917. https://doi .org/10.1002/he c. 3557

[20] Dervaux B, Ferrier GD, Leleu H, et al. Comparing French and US hospital technologies: a directional input distance function approach. Applied Economics. 2004; 36(10): 065-1081. https : //doi.org/10.1080/0003684042000246786

[21] Mobley IV LR, Magnussen J. An international comparison of hospital efficiency: does institutional environment matter? Applied Economics. 1998; 30(8): 1089-1100. https ://doi.org/10.108 $0 / 000368498325255$

[22] Rosko MD, Mutter RL. Stochastic frontier analysis of hospital inefficiency: a review of empirical issues and an assessment of robustness. Medical Care Research and Review. 2008; 65(2): 131-166. PMid:18045984. https ://doi .org/10.1177/10775587073075 80

[23] Deily ME, McKay NL, Dorner FH. Exit and inefficiency: The effects of ownership type. Journal of Human Resources. 2000; 35(4): 734-747. https ://doi.org/10.2307/146370

[24] Rosko MD, Mutter RL. Inefficiency differences between critical access hospitals and prospectively paid rural hospitals. J Health Polit Policy Law. 2010; 35(1): 95-126. PMid:20159848. https: //doi.org/10.1215/03616878-2009-042

[25] McKay NL, Deily ME, Dorner FH. Ownership and changes in hospital inefficiency, 1986-1991. Inquiry. 2002; 39(4): 388-399.
PMid:12638713. https://doi.org/10.5034/inquiryjrnl_39 .4 .388

[26] Ozcan YA, Luke RD. A national study of the efficiency of hospitals in urban markets. Health Serv Res. 1993; 27(6): 719-739.

[27] Jehu-Appiah C, Sekidde S, Adjuik M, et al. Ownership and technical efficiency of hospitals: evidence from Ghana using data envelopment analysis. Cost Eff Resour Alloc. 2014; 12(1): 9. PMid:24708886. https ://doi.org/10.1186/1478-7547-12-9

[28] Rosko MD, Goddard J, Al-Amin M, et al. Predictors of Hospital Profitability: A Panel Study Including the Early Years of the ACA Journal of Health Care Finance. 2018; 44: 3.

[29] Hadley J, Zuckerman S, Iezzoni LI. Financial pressure and competition: changes in hospital efficiency and cost-shifting behavior. Med Care. 1996; 304(3): 205-219. PMid:8628041. https : //doi.org/10.1097/00005650-199603000-00002

[30] Tiemann O, Schreyögg J, Busse R. Hospital ownership and efficiency: A review of studies with particular focus on Germany. Health Policy. 2012; 104(2): 163-171. PMid:22177417. https: //doi.org/10.1016/j.healthpol.2011.11.010

[31] Kruse FM, Stadhouders NW, Adang EM, et al. Do private hospitals outperform public hospitals regarding efficiency, accessibility, and quality of care in the European Union? A literature review. Int J Health Plann Mgmt. 2018; 33: e434-e453. PMid:29498430. https://doi.org/10.1002/hpm. 2502

[32] Posnett J. Are bigger hospitals better? In McKee M, Healy J (Eds.). Hospitals in a changing Europe. World Health Organization: European Observatory of Health Care Systems series; 2002.

[33] Goudie R, Goddard M. Review of evidence on what drives economies of scope and scale in the provision of NHS services, focusing on A\&E and associated hospital services. Centre for Health Economics, University of York: A report for the OHE Commission on Competition in the NHS; 2011.

[34] Athanassopoulos A, Gounaris C. Assessing the technical and allocative efficiency of hospital operations in Greece and its resource allocation implications. European Journal of Operational Research. 2001; 133(2): 416-431. https ://doi .org/10 .1016/S0377-221 $7(00) 00180-6$

[35] Gok MS, Sezen B. Analyzing the ambiguous relationship between efficiency, quality and patient satisfaction in healthcare services: the case of public hospitals in Turkey. Health policy. 2013; 111(3): 290300. PMid:23769176. https://doi.org/10.1016/j.healthpo 1.2013.05.010

[36] Roh CY, Jae Moon M, Jung C. Measuring performance of US nonprofit hospitals: do size and location matter? Public Performance \& Management Review. 2010; 34(1): 22-37. https ://doi.org/10 .2753/PMR1530-9576340102

[37] Giancotti M, Guglielmo A, Mauro M. Efficiency and optimal size of hospitals: results of a systematic search. PLoS ONE. 2017; 12(3): e0174533. PMid:28355255. https : //doi .org/10.1371/journa 1.pone. 0174533

[38] Carey K, Burgess JF, Young GJ. Specialty and full-service hospitals: a comparative cost analysis. Health Serv Res. 2008; 43(5 Pt 2): 1869-1887. PMid:18662170. https://doi.org/10.1111/j. 1475-6773.2008.00881.x

[39] Freeman M, Savva N, Scholtes S. Economies of scale and scope in hospitals. Cambridge: Judge Business School, University of Cambridge, Working Paper; 2016. Available from: https : //www.jbs.cam.ac.uk/fileadmin/user_upload/re search/centres/health/downloads/160629_economiesof scalenandscope.pdf (accessed 20 Sept. 2019).

[40] Weaver M, Deolalikar A. Economies of scale and scope in Vietnamese hospitals. Soc Sci Med. 2004; 59(1): 199-208. 
PMid:15087154. https://doi.org/10.1016/j.socscimed.20 03.10 .014

[41] Grosskopf S, Margaritis D, Valdmanis V. Comparing teaching and non-teaching hospitals: a frontier approach (teaching vs. nonteaching hospitals). Health Care Management Science. 2001; 4(2): 83-90. PMid:11393745. https://doi.org/10.1023/A:101144 9425940

[42] Simmer TL, Nerenz DR, Rutt WM, et al. A randomized, controlled trial of an attending staff service in general internal medicine. Medical Care. 1991; 29(7 Suppl): JS31-JS40.

[43] Grosskopf S, Margaritis D, Valdmanis V. The effects of teaching on hospital productivity. Socio-Economic Planning Sciences. 2001; 35(3): 189-204. https://doi.org/10.1016/S0038-012 1 (01) 00006-4

[44] Yildiz MS, Heboyan V, Khan MM. Estimating technical efficiency of Turkish hospitals: implications for hospital reform initiatives. BMC Health Serv Res. 2018; 18(1): 401. PMid:29866154. https : //doi.org/10.1186/s12913-018-3239-y

[45] Ermann D, Gabel J. The changing face of American health care: Multihospital systems, emergency centers, and surgery centers. Medical Care. 1985; 23(5): 401-420. PMid:3892180. https://doi.org/ 10.1097/00005650-198505000-00006

[46] Rosko MD, Wong HS, Mutter R. Characteristics of High-and LowEfficiency Hospitals. Med Care Res Rev. 2017; 75(4): 454-478. PMid:29148325. https ://doi .org/10.1177/10775587166891 97

[47] Rosko MD, Proenca J, Zinn JS, et al. Hospital inefficiency: what is the impact of membership in different types of systems? Inquiry. 2007; 44(3): 335-349. PMid:18038868. https ://doi.org/10.5 034/inquiryjrnl_44.3.335

[48] Besstremyannaya G. Managerial performance and cost efficiency of Japanese local public hospitals: A latent class stochastic frontier model. Health Economics. 2011; 20(Suppl 1): 19-34. PMid:21809411. https://doi.org/10.1002/hec.1769

[49] Mujasi PN, Asbu EZ, Puig-Junoy J. How efficient are referral hospitals in Uganda? A data envelopment analysis and tobit regression approach. BMC Health Serv Res. 2016; 16: 230. PMid:27391312. https://doi.org/10.1186/s12913-016-1472-9

[50] Xenos P, Nektarios M, Constantopoulos A, et al. Two-stage hospital efficiency analysis including qualitative evidence: A Greek case. Journal of Hospital Administration. 2016; 5: 3. https://doi.org/ $10.5430 / j h a \cdot v 5 n 3 p 1$

[51] OECD. Health at a Glance: Europe 2012. Paris: OECD Publishing; 2012.

[52] OECD/EU. Health at a Glance: Europe 2018: State of Health in the EU Cycle. Paris: OECD Publishing; 2018.

[53] Morrill RL, Symons J. Efficiency and equity aspects of optimum location. Geographical Analysis. 1977; 9(3): 215-225. https: //doi.org/10.1111/j.1538-4632.1977.tb00575.x

[54] Rezaee MJ, Karimdadi A. Do geographical locations affect in hospitals performance? A multi-group data envelopment analysis. J Med Syst. 2015; 39(9): 85. PMid:26208596. https://doi.org/10.1 007/s10916-015-0278-3

[55] Gaynor M, Moreno-Serra R, Propper C. Death by market power: reform, competition, and patient outcomes in the National Health Service. American Economic Journal: Economic Policy. 2013; 5(4): 134-66. https://doi.org/10.1257/pol.5.4.134

[56] Goddard M. Competition in healthcare: Good, bad or ugly? Int J Health Policy Manag. 2015; 4(9): 567-569. PMid:26340484. https://doi.org/10.15171/ijhpm.2015.144
[57] Siciliani L, Chalkley M, Gravelle H. Policies towards hospital and GP competition in five European countries. Health Policy. 2017; 121(2): 103-110. PMid:27956096. https://doi.org/10.1016/j.heal thpol.2016.11.011

[58] Lee KH, Park J, Lim S, et al. Has competition increased hospital technical efficiency? Health Care Manag. 2015; 34(2): 106-112. PMid:25909397. https://doi.org/10.1097/HCM. 0000000000 000061

[59] Narci HÖ, Ozcan YA, Şahin İ, et al. An examination of competition and efficiency for hospital industry in Turkey. Health Care Manag Sci. 2015; 18(4): 407-418. PMid:25515038. https ://doi.org/10 $.1007 / \mathrm{s} 10729-014-9315-\mathrm{x}$

[60] Chang CF, Troyer JL. The impact of TennCare on hospital efficiency. Health Care Manag Sci. 2009; 12(3): 201-216. PMid:19739355. https://doi.org/10.1007/s10729-008-9084-5

[61] Biørn E, Hagen TP, Iversen T, et al. How different are hospitals' responses to a financial reform? The impact on efficiency of activity-based financing. Health Care Manag Sci. 2010; 13(1): 116. PMid:20402278. https://doi.org/10.1007/s10729-009 $-9106-\mathrm{y}$

[62] Guterman S, Dobson A. Impact of the Medicare prospective payment system for hospitals. Health Care Financ Rev. 1986; 7(3): 97.

[63] Dismuke CE, Sena V. Has DRG payment influenced the technical efficiency and productivity of diagnostic technologies in Portuguese public hospitals? An empirical analysis using parametric and non-parametric methods. Health Care Manag Sci. 1999; 2(2): 107-116. PMid:10916607. https://doi.org/10.1023/A : 1019027509833

[64] Linna M. Health care financing reform and the productivity change in Finnish hospitals. J Health Care Finance. 2000; 26(3): 83-100.

[65] McKee M, Healey J. The significance of hospitals: an introduction In McKee M, Healey J (Eds.). Hospitals in a changing Europe. World Health Organization: European Observatory of Health Care Systems; 2002.

[66] Chalkley M, Sussex J. Private provision of publicly funded health care: the economics of ownership. OHE Briefing, London: Office of Health Economics; 2018. Available from: https://www .ohe.org/publications/private-provision -publicly-funded-health-care-economics-ownership (accessed 14 February 2019).

[67] Herrera CA, Rada G, Kuhn-Barrientos G, et al. Does ownership matter? An overview of systematic reviews of the performance of private for-profit, private not-for-profit and public healthcare providers. PLoS One. 2014; 9(12): e93456. PMid:25437212. https: //doi.org/10.1371/journal.pone.0093456

[68] Charlesworth A, Or Z, Pencelayh E. Efficiency measurement for policy formation and evaluation. In Cylus J, Papanicolas I, Smith PC (Eds.). Health system efficiency: How to make measurement matter for policy and management. WHO: European Observatory on Health Systems and Policies, Health Policy Series 46; 2016

[69] Rosko MD, Chilingerian JA. Estimating hospital inefficiency: does case mix matter? Med Syst. 1999; 23(1): 57-71. PMid:10321380. https://doi.org/10.1023/A:1020823612156

[70] Hollingsworth B, Street A. The market for efficiency analysis of health care organisations. Health Econ. 2006; 15(10): 1055-1059. PMid:16991208. https://doi.org/10.1002/hec.1169

[71] Castelli A, Street A, Verzulli R, et al. Examining variations in hospital productivity in the English NHS. Eur J Health Econ. 2015; 16(3): 243-254. PMid:24566702. https://doi .org/10.1007/s10198 $-014-0569-5$ 